\title{
EFEITO DO HEXAMETONIO SOBRE A CONTRATILIDADE DE MÚSCULO LISO DE COBAIOS PROVOCADA PELO EXTRATO AQUOSO DO FUNGO Ramaria
}

Flavo Brunnescens*

Ana Maria Chagas, Zuleica Tabarelli, Ruben Boelter, Lisandre Kipper, Rejane Mello Flores e José Antônio Aguilar Vaca

Departamento de Fisiologia. Centro de Ciências da Saūde.UFSM. Santa Maria, RS

RESUMO

No sul do paỉs encontra-se um fungo denominado Ramaria flavo brunnescens que prolifera em bosques de eucalipto e que pro duz envenenamento de animais através de sua ingestão. As substâncias contidas nesse fungo responsaveis por tal envenenamento ainda não possuem antídoto e evita-se o quadro tóxico nos animais, retirandoos das pastagens onde existem bosques de eucalipto e tem-se emprega do, como tratamento sintomático rotineiro a atropina.

Para esclarecer o mecanismo de ação do extrato aquoso des se fungo sobre a contratilidade de músculo liso de cobaios, utiliza ram-se îleos isolados de cobaio em banho-Maria de Magnus, utilizan do transdutor de força acoplado ao fisiōgrafo (marca Harvard, USA). As experiências foram realizadas em 18 preparações de îleo de co baios isolados, conforme tēcnica descrita acima. As substâncias e concentrações testadas atravēs de adição ao banho, seleciona das em experiências-piloto foram as seguintes: 10 microgramas de $n \underline{i}$ cotina; 24.600 microgramas de extrato aquoso do fungo Ramaria flavo brunnescens; e 30 microgramas de Hexametōnio.

A adição do extrato do referido fungo produz uma contra ção da musculatura lisa semelhante àquela provocada pela nicotina, diferindo dessa porque não é bloqueada pelo hexametōnio. Isso induz a pensar que a morte dos animais que ingerem o fungo não seja provo cada por estimulação ganglionar.

SUMMARY

CHAGAS, A.M.; TABARELLI, Z.; BOELTER, R.; KIPPER, L.; FLORES, R. M. and VACA, A.A., 1986. Hexametonium effect on the contraction of the smooth muscle. Ciēncia e Natura, 8:67-71.

Animals poisoning by ingestion of Ramaria flavo brunnescens fungus found in Eucalipto groves is common in Southern Brazil.

This poisoning does not have an effective antidote yet and $i t$ is common to avoid the toxicity by removing the animals from these fields or by using atropin when fungus intoxication signals

* Trabalho realizado com suporte financeiro do convênio FINEP/UFSM a través do NPPN. 
appear.

Present work was reallized to elucidate the manner and place of action of this fungus aqueous extract on isolated guinea pig ileum. For this purpose, we used Magnus Bath and strain transducer to Physiograph connect. Experiences were realized with 18 ileum tested with $10 \mathrm{mcg} N$ icotine, $24.600 \mathrm{mcg}$ Ramaria flavo brunnescens fungus' aqueous extract and $30 \mathrm{mcg}$ Hexametonium. Those concentrations were choosen from pilot experiences.

The results showed that uses of this fungus extract provokes smooth muscle contraction similar to that of nicotin, the difference between both occurs due to Hexametone blockade impossibility.

This fact suggests that the death mechanism of animals that eat this fungus is not due to ganglionar stimulation.

INTRODUÇAO

0 pouco conhecimento sobre a toxidade de fungos e outras plantas conduz à sērios problemas e geralmente os quadros tóxicos possuem tratamento apenas sintomātico, tanto no homem como nos an mais.

A fungo Ramaria flavo brunnescens prolifera em solo sob bosques de eucalipto, nas regiões do Rio Grande do Sul e São Paulo, segundo Corner(5).

Fidalgo e Fidalgo(6) afirmaram que foi noticiado no Jor nal do Brasil em 1963, que o gado encontrado em campus com matos de eucalipto era acometido de doença denominada "Mal do Eucalipto". Se gundo Barros(1) em 1958 e Bauer et alij(2), essa doença foi observa da em bovinos e ovinos, sendo a ēpoca de ocorréncia, os primeiros meses do ano.

Santos et alij(7) observaram a sintomatologia clinica co mo sialorréia, perda de pelos da cauda, descamação de epitēlio, prin cipalmente de līngua e boca, hemorragia do globo ocular e cegueira, desprendimento de cascos e chifres, e estabeleceram as doses tōxi cas como sendo $5 \mathrm{~g} / \mathrm{kg} / \mathrm{dia}$ para aparecimento dos sintomas e $20 \mathrm{~g} / \mathrm{kg}$ durante 18 dias para provocar a morte.

Chagas et alij(4), estudando o modo de ação do extrato aquoso do fungo Ramaria flavo brunnescens em illeo de cobaias, obser varam que ocorre contração semelhante à acetilcolina mas que essa estimulação não é bloqueada pela atropina.

Com base no exposto, os autores estudarão o mecanismo des sa contração e verificarão se a mesma è do tipo nicotỉnico.

MATERIAL E METODOS

Preparo do Extrato: o fungo Ramaria fluvo brunnescens foi coletado em solo com eucalipto nas proximidades de Santa Maria, RS 
e identificado por comparação com a descrição de Fidalgo e Fidal go (6) Logo após coletado, $360 \mathrm{~g}$ do fungo foram triturados em 1 iqui dificador com $60 \mathrm{ml}$ de āgua desionizada e filtrado com papel filtro. Do filtrado foi preparado o extrato contendo $24.600 \mathrm{mcg} / \mathrm{ml}$.

Procedimento: As experiências foram realizadas em 18 îleos de cobaias de ambos os sexos, de idade e pesos variāveis. Os ani mais foram mantidos no Biotērio do Departamento de Fisiologia da UFSM, por 36 horas, à uma temperatura de $24^{\circ} \mathrm{C}\left( \pm 2{ }^{\circ} \mathrm{C}\right)$, com āgua e alimento "ad libitum", visando ambientação.

Apōs, os animais foram sacrificados por pancada na cabeça e sangria imediata por secção dos vasos cervicais. A cavidade abdo minal foi aberta e retirada uma porção de $6 \mathrm{~cm}$ de ỉleo terminal que foi mantida em solução de Tyrode oxigenada à $37^{\circ} \mathrm{C}$, livre de seu con teūdo e de suas conexões com o mesentērio. A seguir foi tomado um segmento de aproximadamente $3 \mathrm{~cm}$, que foi levado ao banho de Magnus com 25ml de soluçäo de Tyrode oxigenada e à mesma temperatura de $37^{\circ} \mathrm{C}$. Uma de suas extremidades foi fixada à uma haste de vidro e a outra à uma alavanca do miōgrafo acoplada ao eletromiōgrafo do Fisiōgrafo (marca Harvard, USA).

0 experimento constou da medida da amplitude das contra ções (expressa em mm) dos 11 eos apōs o uso das duas drogas e do ex trato do fungo no banho. A primeira medida foi efetuada após a colo cação de $10 \mathrm{mcg}$ de nicotina no banho. Logo apōs efetuaram-se trēs lavagens consecutivas dos $\nmid l e o s$ isolados. Adicionando-se o extrato do fungo ao banho, houve contração da musculatura, esta foi medida, novamente três sucessivas lavagens e assim sucessivamente. As medi ções seguintes foram efetuadas na vigēncia de 30 mcg de Hexametōnio e das outras duas soluções em estudo.

\section{RESULTADOS}

Analisando-se a tabela I, observa-se que tanto a nicotina como o extrato aquoso do fungo produzem contração da musculatura $1 \underline{i}$ sa. A nicotina produziu uma contração maior, de $76,7 \mathrm{~mm}$, enquanto que a produzida pelo extrato aquoso do fungo foi de $63,2 \mathrm{~mm}$.

Após efetuada a lavagem da preparação foram colocados 30 mcg de hexametōnio (droga padrão de bloqueio ganglionar ou do efe to estimulante da nicotina). Essa droga produziu um relaxamento da musculatura lisa, como era esperado. Na vigência do hexametônio foi adicionado ao banho de Magnus $10 \mathrm{mcg}$ de nicotina e a mesma não apre sentou contração, mostrando assim que o hexametônio havia produzido seu bloqueio. Depois da lavagem da preparação, foi colocada a mesma quantidade de hexametônio e $24.600 \mathrm{mcg}$ de extrato aquoso do fungo Ramaria flavo brunnescens e houve contração de $65,7 \mathrm{~mm}$. 
TABELA I - VALORES MEdIOS DAS CONCENTRAÇOES MUSCULARES dO MÚSCULO LISO DE ILEO DE COBAIOS, EXPRESSOS EM MILIMETROS, APOS A ADIÇAO DE NICOTINA ( $10 \mathrm{MCG}$ ), DO EXTRATO AQUOSO DO FUNGO Ramaria flavo brunnescens (24.600 MCG) E DE HEXAMETÕNIO (30 MCG). BLOQUEIO DA AÇÃO DA NICOTINA PELO HEXAMETŌNIO E INEXISTENCIA DESSA AÇAO COM O USO DO EXTRATO DO FUNGO.

\begin{tabular}{|c|c|c|c|}
\hline \multirow[t]{2}{*}{$\begin{array}{l}\text { Nicotina } \\
(10 \mathrm{mcg})\end{array}$} & \multirow{2}{*}{$\begin{array}{l}\text { Extrato aquoso do } \\
\text { fungo Ramaria fla } \\
\text { vo brunnescens } \\
(24.600 \mathrm{mcg})\end{array}$} & \multicolumn{2}{|r|}{$\begin{array}{l}\text { Hexametōnio } \\
\text { (30 mcg) }\end{array}$} \\
\hline & & $\begin{array}{l}\text { Nicotina } \\
(10 \mathrm{mcg})\end{array}$ & $\begin{array}{c}\text { Extrato do fungo } \\
(24.600 \mathrm{mcg})\end{array}$ \\
\hline $77,7+1,32$ & $63,2+1,48$ & 0 & $65,7+1,77$ \\
\hline
\end{tabular}

\section{DISCUSSAO}

A ação do extrato aquoso do fungo Ramaria flavo brunnescens sobre o músculo de $\mathbf{1} l e o$ isolado de cobaios produz uma contração se melhante à da nicotina, mas a mesma não é bloqueada pelo hexametō nio. Em trabalnos anteriores Chagas et alii (4) observaram que a con tração produzida no $¥ 1$ eo pela administração, no banho, de extrato do fungo Ramaria flavo brunnescens não é do tipo muscarīnico, uma vez que não é bloqueada pela atropina. Sabe-se que a estimulação gan glionar poderā induzir uma liberação de acetilcolina, com estimula ção à nỉvel periférico $(3,8)$.

Poderia o hexametônio bloquear a contração produzida pelo referido extrato? Sim, desde que essa contração fosse provocada por uma estimulação nos receptores nicotỉnicos.

Então administrou-se o extrato do fungo na vigēncia do he xametônio e obteve-se uma contração semelhante à primeira, mostran do assim que não houve bloqueio e por isso a contração provocada pelo fungo não è do tipo nicotīnico.

No entanto, na terapêutica veterināria é frequente o uso de anticolinérgicos para diminuir a sintomatologia dos animais enve nenados por esse fungo. Mesmo não havendo bloqueio, isso é aconse Ihāvel porque auxilia a autorregulação dos animais, estimulando os mecanismos neuro-humorais interligados, diminuindo a diarréia e a salivação que são bastante intensas nesses casos.

\section{CONCLUSOES}

Conclui-se que $24.600 \mathrm{mcg}$ de extrato aquoso do fungo $R \underline{a}$ maria flavo brunnescens produz uma contração da musculatura lisa do ileo de cobaio, semelhante àquela produzida por $10 \mathrm{mcg}$ de nicotina 
e o hexametēnio não bloqueia essa contração, não havendo, por isso, ação tipo nicotínica do referido extrato.

BIBL IOGRAFIA CITADA

1. BARROS, S.S.: Da possível incidência da toxicose pelo selênio em bovinos no Rio Grande do Sul. Dipan.:11(121-2):10-3, 1958.

2. BAUER, A.G.; LARANJA, R.J.; SANTOS, A.G.: Sobre a etiologia do chamado "Mal do Eucalipto". Arquiv. Instit. Pes. Vet. Desidé rio Einamor, 3: 85-90, 1960.

3. BEVAN, J.A.; Fundamentos de Farmacologia, São Paulo, Editora Har per \& Row do Brasil, pp 589, 1979.

4. CHAGAS, A.M.; PIRES, T.E.; MAGALHAES, H.M.: Atividade da atropi na como provāvel bloqueadora do extrato aquoso do fungo Rama ria flavo brunnescens na musculatura lisa. Rev. Centro de Ciências Rurais, 8(3):211-6, 1978.

5. CORNER, E.J.T.: Species of Ramaria (Clavariaceas) without clamps. Br. Mycol. Soc., 49(1):101-13, 1966.

6. FIDALGO, 0 \& FIDALGO, M.E.P.K.: A poisonous Ramaria from Southern Brazil. Rickia, 5:71-91, 1966.

7. SANTOS, M.N.; BARROS, S.S.; BARROS, S.L.: Intoxicações em bov $i$ nos pelo cogumelo Ramaria flavo brunnescens. Pesq. Agropec. Bras., 10:105-9, 1975 .

8. ZANINI, A.C.; OGA, S.: Farmacologia aplicada, São Paulo, Editora Atheneu, pp 625, 1979.

Recebido em setembro, 1986; aceito em outubro, 1986. 
